\title{
ANTES DEL PENSAR: LAS AVENTURAS DEL 'ERGO' DESDE DESCARTES HASTA HEIDEGGER
}

Raúl Gabás

(Universitat Autònoma de Barcelona)

\section{Las aventuras históricas del "ergo"}

Desde Descartes hasta Husserl se desarrolla una figura de fundamentación filosofica que a partir del pensar autointuyente quiere alcanzar el ser mediante alguna conexión reflexiva o lógica, que en mi enunciado se simboliza con el "ergo". ¿Cómo ha de concebirse la conexión entre pensar y ser? Puede alcanzarse el ser cuando el punto de partida es el pensamiento? La forma de ver esa conexión es el hilo conductor de la filosofia moderna, y podria decirse que la modernidad filosófica acaba cuando se devuelve al ser la soberania sobre el pensar (ontologización del neokantismo, reconducción de la fenomenologia hacia el mundo de la vida). El punto decisivo en esta inflexión es la ontologia fundamental de Martin Heidegger. El camino que le precede está jalonado por Descartes, el idealismo alemán y la fenomenologia.

Sin embargo, en el intento de superación de la fillosofia del yo, de la filosofia de la conciencia, de la primacia del pensamiento sobre el ser, no se trata solamente de un transcurso histórico sucesivo, sino, además, de un problema presente en los momentos mismos de apogeo de la subjetividad. En el propio Descartes el yo nunca pasa a ser principio único y primero de la realidad. Pero la función decisiva del "yo pienso" en la fundamentación del saber pasa luego a la apercepción trascendental de Kant como acto supremo de transparencia y garante de la validez de los juicios. Se anade a esto la importancia del "intellectus arquetypus", aunque sólo sea como foco contrastante con la finitud. El "intellectus arquetypus" sugiere por lo menos el ideal de un pensar capaz de dar fuerza intuitiva a su pensamiento.

El momento más fuerte de conexión entre el yo y las representaciones se produce en Fichte, que asume el legado de Descartes y Kant radicadizándolo lasta límites que antes de ét nadie habia osado alcanzar. Su intento de deducción de toda la realidad a partir del yo, de unn yo que adquiere conciencia de si en el acto pensante por el que es opuesto el no-yo como representación, impulsó aquella cadena de sistemas que conocemos como idealismo alemán. Fichte mismo terminó renunciando a cifrar el fundamento absoluto en el yo, e introdujo en su lugar un ser previo al acto de escisión que se da en el pensar por el que se produce la conciencia de si. $Y$ en las obras de Schelling y Fichte es decisivo el intento de superar cl sujeto-objeto meramente pensado del Fichte inicial. No fue pequeño el impacto de los filósofos poetas, sobre todo el de Scliller y Hölderlin, en orden a la superación de un pensamiento que dicta por sí mismo el cauce del ser y que, por ello, oprime la sensibilidad y carece de fuerza para erigirse en fundamento. Schopenhauer, que prepara la cuna de Nietzsche, se burla de los despropósitos de convertir el entendimiemnto humano en fundamento metafisico del mundo. Que algo invisible (la libertad) se traduzca a lo visible, era ya un punto decisivo en la estética de Kant, que habla de lo bello como simbolo de la moralidad. Schopenhauer recurre al imperceptible artificio de Ilamar "voluntad" a la "libertad" kantiana, pero despojándola de toda conexión directa con lo inteligible, con el intelecto, que como "servum pecus" queda encadenado en las anillas de los enlaces fenoménicos.

El nuevo ciclo importante de pensamiento se erige con la fenomenologia, que transmite el legado cartesiano al siglo $\mathrm{xx}$, pero superando el dualismo mediante una reinterpretación de la duda tal como se expresa en el concepto de "epoje”. El montento metódico de poner entre 
paréntesis la existencia no implica una separación substancial de lo sensible e intuitico frente al pensamiento significante.

\section{Descartes y Heidegger}

Descartes y Heidegger son los exponentes más característicos de dos épocas de la filosolia: la moderna y la que se instaura al final de la modernidad. La filosofia de cada uno de ellos acostumbra a sintetizarse mediante dos palabras enlazadas por un guión: "cogito-sum", y "serahi". Ambos coinciden en que el hombre goza de una especial proximidad al ser y es el lugar ontológico por excelencia. Media entre los dos una cercania y una distancia abismal. Como en trenes que en su trayecto se separan progresivamente, pequeñas diferencias en cl punto de partida conducen a lugares opuestos en el punto de llegada.

La discusión explicita con Descartes aflora en algunos pasajes de Ser y tiempo, y continúa luego en La pregunta por la cosa, entre otros escritos. Pero ya en el enfoque general de Ser y tiempo el cartesianismo es un horizonte constantemente presente. Descartes es la única alternativa que Heidegger analiza de cara a la explicación del mundo. Por tanto, la obra mencionada debe leerse en clave cartesiana. No es casual que Heidegger arranque de la pregunta como modo de ser del hombre. La pregunta puede equipararse a la duda cartesiana. Heidegger desarrolla la estrategia de mostrar que un análisis fenomenológico de la duda no conduce inmediatamente a un estrato evidencial de la existencia, sino, irónicamente, a la "existencia" en un sentido diametralmente opuesto. En la rampa de lanzamiento está la pregunta y está la existencia. Sin embargo, ¿cuảl es el sentido último de la duda y de la existencia? ¿Cuál es la verdadera relación entre dudar y existir? Dando por supuesto que Ser y tiempo, como nuevo intento de construcción de una ontologia fundamental, signitica en su totalidad una ríplica a Descartes, seguidamente trataremos por separado el diálogo indirecto con Descartes y la disputa directa.

\section{a) El diálogo indirecto con Descartes}

La posición de Heidegger venia preparada por una larga trayectoria anterior en la que ocupan un lugar señalado las lecciones del semestre de invierno de 1919-1920, llamado también semestre de la guerra. Heidegger defiende alli que lo teorético, el mundo de la ciencia, surge de un esfera preteorética, denominada "facticidad". Esta esfera fáctica recibe también la denominación de "algo originario premundano". El algo originario es una esfera de la vida en la que todavia no se han diferenciado entes determinados, es una indiferenciada diferenciabilidad, es un no-ente.' Desde el algo originario mundea el mundo. Cada mundo concreto apunta hacia este algo, que se presentra vivencialmente como "dirección hacia", o "referencia a", o "comportarse con". El algo originario es la cosa simple que se sustrae. La fuente escondida de la vida se muestra mundeando en el mundo, aunque podamos acceder a ella conceptualmente.

Heidegger pasará al diálogo directo con Descartes cuando haya destruido las bases de su argumentación. El primer paso consiste en hundir el puente cartesiano entre el yo y el mundo por medio de la substancia infinita. En efecto, el tema de Dios para nada aparece a través de la obra. De los tres ámbitos metafisicos tradicionales: Dios, alma y mundo, sólo el yo y el mundo quedarán reflejados en la nueva ontologia. Sin embargo, desde el momento en que el autor introduce la expresión ser-en-el-mundo nos a anuncia la fusión del hombre y del mundo en una

1 Theodor Kisiel, Heidegger's Durchbruch zm hermenemischer Phänomenologie, en "Pluilosophisches Jalurbucli" 99 (1992) 
unidad indivisible. En medio de esta unidad se replantea la ontologia fundamental. Con ello se cierra el camino seguido por Descartes y por Fichte. Fenomenológicamente no es posible para Heidegger una fundamentación ontológica a partir de la evidencia del yo.

El segundo golpe en el camino de erosión del cartesianismo consiste en destruir o volatilizar el subsuelo de la substancialidad. El desarrollo de esta tarea ocupa la mayor parte de la obra. No obstante, el trabajo más fuerte se lleva a cabo en el proceso que conduce a la detinición de la mundanidad del mundo. Pertrechado con las armas de los análisis husserlianos, y en particular con el dinamismo que lusserl confiere a la significación frente al cumoplimiento significativo, Heidegger libra la primera batalla en la distinción entre lo que es "a la mano" (Zuhanden) y lo que es "ante los ojos" (Vorhanden). En la persistente luclia contra la primacía de lo que es ante los ojos, no lay duda de que Heidegger lucha contra la ontologia de substancias o cosas invariantemente accesibles a través de la mirada (intuición, pensamiento claro...). $Y$ no le basta con establecer una distinción entre los existenciarios y las categorias. sino que deduce las segundas a partir de las primeras. Con el análisis existenciario se coloca la piedra angular de la nueva ontologia. Está claro que lo existenciario se refiere a la existencia, a una existencia inherente a la duda en sentido cartesiano, pero mal interpretada en el proceso intelectual de Descartes. Los paràgrafos contemnidos en el capitulo primero de la introducción a Ser y tiempo son algo más que un simple prólogo. En ellos se encuentra la clave de bóveda, el primer resumen y la articulación de la obra. Esta comienza propiamente en el parágrafo segundo, titulado: La estructura formal de la pregunta por el ser. Alli aparecen las siguientes alirmaciones:

Lo peculiar de la pregunta explicita estí en que el preguntar mismo ha de hacerse transparente en todos los mencionados caracteres constitutivos de la pregunta misma.

\section{Y seguidamente:}

El preguntar, como búsqueda, necesita una dirección previa por parte de lo buscado.

Esto significa que lo preguntado, el ser, da un indicio de si mismo a través del preguntar como manera de ser del lombre. El tema mencionado encuentra su continuación en el parígrafo cuarto. En él hallamos la afirmación:

La analitica existenciaria. por su parte, tiene en último ténnino raices existenciales, es decir, ónticas. Sólo tomando el preguntar filosófico mismo existencialmente o como posibilidad de ser del 'ser ahj" existente en cada caso, Inay la posibilidad de que se abra la existenciaridad de la existencia y la posibilidad de atacar los probleanas ontológicos con suficiente fundamento. ${ }^{2}$

En el comportamiento correlativo de ser y existencia está en juego un movimiento entre posibles maneras de ser. Ser sí mismo o no serlo, elegir entre diversas posibilidades, no son meras incidencias antropológicas, sino que se hallan insertas en el reino del ser en cuanto tal. El yo es un fenómeno interno al acontecer del ser mismo. Un yo que füera substancia permanente no tendria problema de ser. de él no podria decirse que "en su ser está en juego su ser".

Junto con el concepto de existencia Heidegger saca a la escena la "posibilidad". Y desde el terreno así conquistado analiza el ser-en-el-mundo. En el "nirar en tomo" de la vida prác-

2 Sein tund Zeit, Tulinga, Niemeyer 1957, p. 13, trad. FCE. p. 23. 
tica, no de la contemplacion teórica, se constituyen el "ser a la mano", los todos de conlormidad, los parajes y la munanidad del mundo, que al final es definido mediante la siguiente formulación:

El fenómeno del mundo es el horizonte (Worin) del comprender que "refiere a". como el hacia dónde en el permitir que salgan al encuentro entes bajo la forma de ser de la conformidad (e.c., p. 86).

El mundo es asi un nexo de referencias y posibles maneras de ser, y no algo que se parezca a una substancia.

En el desarrollo de la cuestión del "ser-en" en cuanto tal, que se articula como temple de ánimo, comprender y liabla, ocupa una posición primordial el tema de la verdad como apcrtura, que está presupuesta en la verdad de la proposición. Los grandes pasos del resto de la obra: la estructura de la cura, el ser para la muerte, la negatividad del sí mismo que se anuncia en la conciencia $y$, finalmente, la temporalidad originaria, prosiguen el análisis fenomenológico del no ser inherente a la experiencia inicial de la "existencia". Oigamos uno de los textos más expresivos a este respecto:

\begin{abstract}
El 'ser ahi' es un fundamento existiendo, es decir, de tal manera que se comprende partiendo de posibilidades, y comprendiéndose de esta forma es el ente arrojado. Pero esto implica: 'pudiendo ser', está en cada caso en una u otra posibilidad, constantemente no es otra y ha prescindido de ella en la proyección existencial. La proyección no es sólo determinada como arrojada en cada caso por el "no ser"del "ser el fundamento", sino que en cuanto proyección es el la misma 'no ser'. Esta determinación no significa a su vez en manera alguna la propiedad óntica de lo "fracasado" o "sin valor", sino un ingrediente constitutivo, existenciario, de la estructura del ser del proyectar. El mentado no-ser es inherente al ser en libertad el "ser ahi" para sus posibilidades existenciales. Pero la libertad sólo es en la elección de una, es decir, en el no haber elegido y no poder elegir también otras.
\end{abstract}

b) La disputa directa con Descartes

En la organización del tema del mundo, desde el parágrafo 14 hasta el 24, Heidegger establece tres apartados $(A, B, C)$, el segundo de los cuales está destinado a la discusión con Descartes. Esto confirma que la refutación del enfoque cartesiano es determinante para la articulación de la obra. Tan pronto como acaba de definir el mundo, pasa a la critica explicita del cartesianismo. Repro duce ante todo la definición cartesiana del mundo como "res extensa", como "extensio in longum, latum et profundum". Toda otra propiedad presupone la extensión, y ésta, como propiedad fundamental, nos da el acceso cognoscitivo al ser de la substancia. Resalta Heidegger sobre todo que en Descartes la substancia, en cuanto permanencia constante, constituye el verdadero ser. Al tratar seguidamente de los "fundamentos ontológicos" de esta concepción substancialista, le objeta que no aborda el sentido del ser encerrado en la significación de la substancia, el ser que es común a todas las substancias. Más bien, dejándose guiar por el modelo de conocimiento físico-matemático, en el que se da el rasgo de la constancia permanente, le dicta al mundo su ser. Descartes, continúa Heidegger, mediante una idea de ñegitimidad no comprobada, le prescribe al mundo su verdadero ser. El privilegio del conocimiemnto matemático, que aprehende en forma excepcionalmente satisfactoria el constante "ser ante los ojos", queda en lazado en Descartes con la ousia y el nocin tradicionales. $Y$ en consecuencia él no pudo llegar hasta los problemas ontológicos originarios del ser-ahí.

Heidegger por su parte ofrece una explicación genética del mundo cognoscitivo del cartesianismo y de la ciencia, asi como de las categorias fundamentales implicadas alli. Caracteriza esta constitución con el término específico de TEMATIZACIÓN. 
Heidegger en ningún momento pone en duda que se da la actividad constitutiva de la ciencia y de sus categorias fundamentales, las cuales implican una visión o intuición de algo que está claro y fijo ante nuestra mirnda. Con ello reconoce la tarea de Descartes, de Husserl y de la ciencia en general. Pero el verdadero problema frente a Husserl y Descartes es el de si lo primera y fundamentalmente manifiesto es la evidencia intuitiva del yo, o, por el contrario, un análisis genuino del problema del yo remite a una apertura previa. De ahi la insistencia en la verdad antepredicativa, que se abre como temple de ánimo, comprender y habla.

\section{c) El sentido de la discusión}

Descartes forjó un nuevo orden metafisico en tomo a la triple substancia, con una indudable primacia noética y ontológica de Dios. Junto con el ser dubitativamente cierto abierto en la "cogitatio" se abre también el fondo más originario de Dios, que es el fondo último desde el que nos cercioramos de la substancia pensante y de la extensa. Yo y mundo deben su claridad a la aprehensión de Dios como lo que confiere una substancialidad derivada. En la tercera de las Meditaciones metafisicas Descartes escribe:

Veo manifiestamente que hay más realidad en la substancia infinita que en la finita, y por lo tanto existe primero en mi la percepción de lo infinito, es decir, de Dios, que de lo finito, es decir, de mi mismo. ¿Cómo podria saber que yo dudo, que deseo, es decir, que me falta algo, y que no soy en absoluto perfecto, si no hubiese una idea de un ser más perfecto en ml, por cuya comparación conociese mis defectos? No obsta a ello que yo no pueda aprehender lo infinito, ni que existan en Dios innumerables otras cosas que ni puedo aprehender, ni tampoco alcanzar siquiera con el pensamiento, puesto que es propio de lo infinito no poder ser concebido por mi, que soy finito.

Si Descartes hablara del ser y no de Dios o de lo infinito, seria posible ver un paralelismo de las palabras citadas con el siguiente texto del parágrafo 2 de Ser y tiempo:

El previo presuponer el ser tiene el carácter de la mirada previa al ser, de tal manera que desde la mirada a él es articulado de manera precursante el ente previamente dado en su ser. Esta mirada directiva al ser emana desde la comprension media del ser, en la que nos movemos ya siempre, y que al final pertenece a la aprehensiỏn de la esencia del ser ahí mismo.

Podria acusarse a Heidegger de que hace una aplicación criptica del argumento ontológico al ser en general, pues a la postre atribuye realidad mundana a todo lo pensado, a todas las significaciones.

Heidegger da por supuesto que Descartes lleva a cabo un gran esfuerzo ontológico. Pero considera que él, en lugar de establecer en la substancia el último fundamento ontológico, hubiera debido preguntarse por el concepto de ser en cuan tal. Los tres ámbitos de la metafísica tradicional: Dios, alma y mundo, se convierten ahora en tres substancias, pero sin replantear la cuestión del ser en cuanto tal. Y aquí es donde Heidegger introduce su gran innovación. En la primera lectura de Ser y tiempo llama la atención la insistencia del autor en la posibilidad en cuanto tal. El lector cree que se halla ante el despliegue de la libertad humana como elección de posibilidades. Sin embargo, la cuestión se vuelve más compleja cuendo en escritos posteriores topamos con afirmaciones como la contenida en la obra Sobre la esencia de la libertad hmmana de Schelling, donde Heidegger escribe: "La incomprensibilidad de la libertad consiste en que ella se resiste a la comprensión en la medida que el ser-libre nos vincula al cumplimiento del ser, y no a la simple representación del mismo. Pero este cumplimiento no es el despliegue ciego de un proceso, sino la insistencia consciente en el seno del ente en su totalidad. este ente 
al que es necesario exponerse con persistencia." ${ }^{3}$ Textos como éste nos inducen a una lectura más detenida de Ser y tiempo bajo la pauta de una revolución ontológica, de una transformación radical del concepto de ser. Las expresiones "cumplimineto del ser y no simple representación del mismo", "cumplimiento que no es cl despliegue ciego de un proceso"..., enlazan colerentemente con los pasajes de diclıa obra donde Hejdegger lucha denodadamente contra la concepción del ser o del yo como substancia, como sustrato siempre presente. El yo substancial de la metafisica tradicional se disuelve en el movimiento de las posibilidades, y ese movimiento queda inserto a su vez en el acontecer del ser como mundear del mundo. Hemos dicho antes que en su ontología fundamental están fusionados el alma y cl mundo, sin que alli aparezca para nada el tema de Dios. Esto va acompañado de una transformación en la tradicional ontología modal, que dividia el ser en posible, existente y necesario. Sugerí esto en mi aniculo El concepto de existencia en Heidegger. 4 Posteriormente he leido un pasaje de Beiträge zur Philosophie en el que el autor dice que el ser para la muerte, acicate de la suprema historicidad, por una parte incluye la pertenencia esencial del "no"al ser como tal, y, por otra parte, alberga la inescrutable plenitud esencial de la "necesidad" como un abismo del ser mismo. Y después de la frase cortada: "La colisión entre necesidad y posibilidad", continúa: "Sólo en tales ámbitos puede barruntarse lo encerrado verdaderamente en lo que la "ontología" trata como la pálida y vacía amalgama de las "modalidades". La transfornación heideggeriana consiste sobre todo en la unificación de esas tres modalidades dentro de la única realidad del ser, pero de tal manera que la posibilidad ocupa una posición mucho más relevante que en la tradiсіо́л. No obstante, podrian encontrarse antecedentes claros en pensadores del pasado. Johannes Brachtendorf, ${ }^{6}$ sin establecer ningún puente con Heidegger, muestra en el Fichte tardio un uso de la palabra ser equivalente a "posible". El principio activo seria la capacidad existente de producción de lo real. Como antecedentes se remite a la tradición metafisica que va de Duns Escoto a Wolff, donde el ser se entiende como capacidad de existir. En Escoto el ser es lo que tiene aptitud para existir. Y para Wolf el objeto de la ontologia es lo que puede existir, lo posible. Es obvio que Heidegger conoce esos antecedentes, sobre todo el de Escoto.

En la nueva fundamentación ontológica lo buscado es una experiencia en la que actúa el ser mismo más allá de su diferenciación en modos y de toda entificación. Diriamos con Heidegger que el punto de partida de Descartes era válido, pero él no se demoró en el ser mismo, sino que condujo precipitadamente el tema hacia un ente originario como fuente substancial. Por tanto, Descartes no desarrolló radicalmente la pregunta que él mismo se había planteado. A su duda habría podido darle el giro de: ¿Cuál es el sentido del ser que se me manifiesta en forma de duda, que me afecta como pregunta, que me descubre en mi finitud? Al centrarse en la evidencia inherente a la respuesta que disipa la duda, Descartes lace imposibla el sentido de la misma. Heidegger, en cambio, arranca de la luz inherente a la pregunta y del esclarecimiemnto de sus implicaciones. Sólo pude preguntar el que no se identifica con lo fijo y permanente. Existencia, pregunta y ser posiblemente son intercambiables. Un ente necesario no preguntaria. Si realmente fueramos una "res", una cosa presente, ¿cómo podriamos dudar de nuestro yo? La respuesta del propio Descartes implica el reconocimioento de un brotar de las representaciones, que pueden cambiar, aparecer y desaparecer, hasta el punto de que quizá tengan un origen

\footnotetext{
3 Schellings Abhandlung juber das Hesen der menschlichen Freihcit, Tubinga. Niemeyer 1971, p. 196.

4 "Anales del seminario da metafisica", número extra 1992, p. 255.

5 GA Klostermann, tomo 65, p. $282 \mathrm{~s}$.

6 Johannes Brachtendorf, Fichtes Lehre von Sein, Paderbon, Schonigh 1995, p. 244-247.
} 
extrano al propio yo. Inicialmente, también en Descartes, lo cuestionado es que lo pensado tenga la condición de cosa a la vista. $Y$ no se cuestiona que se dé la representación en cuanto pensamiento. Con cierta analogia, Heidegger cuestiona que se dé como ser en si mismo lo que es "ante los ojos". Y nunca cuestiona que se dé lo "a la mano".

Heidegger acusa al cartesianismo de que, en su pretendida claridad, oculta lo mis manifiesto, a saber, la acción de lo negativo en el pensar. Él, en cambio, partiendo de una experiencia inmediata equivalente a la de Descartes, y compartiendo con él que en esa experiencia se nos da el ser originario mismo, desarrolla una genuina ontología fundamental En ella lo explorado es el ser en general, aunque no como mero concepto. Los tres modos del ser se funden en una ủnica experiencia, en la que lo más inmediatamente manifiesto es la conducta del hombre como un comportarse con, como un existir inmerso en la posibilidad. La duda no es conducida hacia un estrato a la vista, hacia un bloque substancial y firme donde ella se despoja de su incertidumbre, sino que es tomada como mensajera del ser, como cuestionamiento de todo lo que se me presenta a manera de un reino de cosas, como un reino en el que cotidianamente intento aquietarme. Descartes extiende a todo ello la duda de si "es", $y$ la resuelve relugiándose en un reducto o sustrato que indudable y permanentemente es. Pierde asi el auténtico hilo conductor cle la duda, cuyo sentido es para Heidegger la pregunta por el posible ser del mundo. Y esa pregunta no tiene un carácter meramente teorético, sino que es muclio más radical, ya que pregunta por el venir o no venir a ser de lo que quizá sea. Descartes se angustia por las cosas que ora parecen evidentes, ora engaitosas, oscilando entre lo uno y lo otro. Pero abandona ese dato, tan claramente manifiesto, y se refugia en un reino numénico de substancias, sin entrar todavia en el terreno de la feлomenologin, que introduce el aparecer, la manifestación en el ser mismo, recuperando para El la compañera inseparable, la verdad, como lo manifiesto en si mismo.

En La preginta por la cosa Heidegger interpreta el método cartesiano como una pregunta por el ser del ente, que se cifra en lo matemático como rasgo fundamental del pensar. El ser del ente, dice lleidegger, se determina desde el yo soy como certeza del poner. En ell yo pongo, como sentido del yo soy, esta en juego el primer principio pari el sentido del ente en general. Esa proposición se da a si misma lo que hay en ella. En ella se pone el sujeto, el yo. Diversos intérpretes coinciden con Heidegger en que el cogito es un acto ponente originario, de manera que en Descartes se produce una revolución del cogito en volo. ${ }^{7}$ Carlos Cardona afirma que la existencia del pensamiento pensado pasa a ser acto ponente originario, como autoposición voluntaria, por la remoción voluntaria de aquello cuya existencia me vendria impuesta. Lo primero que el cogito pone es su propia esencia. El yo es la cara escondida de la libertad. de la resolución última del cogito en volo. En Descartes, más que la antigua substancia ontológica, encontramos la conciencia del pensar, que se resuelve en pensamiento y se constituye en principio de si mismo. También Gerhardt Schmidt, en la obra citada , coincide con la interpretación expuesta en que la decisión cartesiana de poner un fundanento nuevo no está funclada, sino que es un acto de voluntad en el que aparece la libertad lumana, es la decisión libre de romper con el saber transmitido. Y Géroult alirma que lo nuevo y peculiar en el orden cartesiano del pensamiento está en que se opone al orden del ser. Lo anterior para mi coincide con lo anterior en si. Pero precisamente esta voluntad epocal es la que Heidegger somete a discusión y quiere reconducir a un nuevo comienzo.

7 La pregmina por la cosa, Alfa Argemina 1975. Carlos Cardona, Discurso del método, Madrid, Critica filosólica 1975; Gerlardd Schmidt, o.c. Gušroult, Descortes selon Iortie des raisons. Gerliard Sclunidt, Alufklarsmg und Aforplyssik, Tubinga, Nismsy'er 1965. 


\section{d) A pesar de las diferencias}

A pesar de las diferencias hay coincidencias entre ambos pensadores. La más clara está en que los dos buscan una nueva fundamentación, uno al principio de la modernidad, otro a final. Descartes rranca de la duda universal sobre todo aquello que los hombres cotidianos de su época consideran verdadero. Va cribando lo más frágil a través de sutiles caminos analíticos hasta encontrar en el "yo pienso-yo soy" el supremo punto de certiza originaria. Desde este momento, ayudado por la idea de Dios y de su perfección, que está implicada en el yo pienso, Descartes recompone una metafisica incuestionable sobtre el yo, Dios y el mundo, una metafisica que, como evidente en si, se contrapone al reino de las apariencias de los sentidos (color, resistencia, etc.), que no gozan de certeza por si mismos, sino que, en el caso de la naturaleza, han de explicarse por el atributo fundamental de la substancia corporal: la extensión. Hecha la nueva fundamentación del conocimiento, queda una clara duplicidad de planos: to que es evidente desde el interior de la mente y el reino falaz de los sentidos. En la Sinopsis de las Meditaciones Descartes dice que muestra las razones por las cuales se puede deducir la existencia de las cosas materiales:

No porque las juzgue muy útiles para probar lo mismo que prueban, es decir, que existe en realidad algún mundo, que los hombres tienen cuerpo,etc., de lo cual nadie que esté en su sano juicio ha dudado nunca, sino porque cuando se las considera, se reconoce que no son tan fimmes ni tan obvins como aquellas mediante las que llegamos al conocimiento de Dios; de manera que éstis ültimas son las mís ciertas y evidentes que pueden ser conocidas por el intelecto hurnano.

Encontramos un proceso comparable en Heidegger. Heredero de la reelaboración del cartesianismo en Husserl, reelaboración que prohibe independizar la actividad del yo frentre al mundo sensible, aquél en Ser y tiempo anuncia que seguirá el método fenomenológico. No puede menos de producir perplejidad el anuncio del método fenomenológico cuando se trata de despedirse del yo como origen constituyente del mundo. La vuelta dada al método fenomenológico consiste en asumir el lema del retorno a las cosas mismas, pero de tal manera que, al llegar a lo que es manifiesto en si mismo, el yo dejará de ser lo primigenio. Heidegger quiere superar a Husserl y a Descartes juntante a través de la profundización en el método fenomenológico.

En el camino hacia las cosas mismas él tiene que abrirse paso a través de apariencias y desfiguraciones hasta Ilegar a lo verdaderamente manifiesto, en definitiva, la temporalidad. ¿No son lo mismo la evidencia de Descartes y lo manifiesto en si mismo de Heidegger? Sin duda es posible un diảlogo entre ambos acerca de lo que es manifiesto. Matarialmente uno y otro sacan a la luz aspectos diferentes. Pero ¿está la discrepancia en la naturaleza de lo manifiesto mismo? Es cierto que el camino de Heidegger consiste en mostrar que lo primeramente manifiesto no es lo pensado, la verdad del enunciado, sino la verdad originaria como apertura. En la apertura se abre el todo del ser-en-el-mundo que es previo al mero decir yo. El mundo no puede articularse analitica o deductiuvamente a partir del mero "yo pienso". Sin embargo, la claridad del pensar en Descartes ¿no tiene también un carácter derivado? ¿Cuál es la claridad de la claridad en ambos pensadores? Para Heidegger, si llegamos al ser que da el pensar, es manifiesto también para el pensamiento el ser que adviene, es decir, la temporaliudad como aurora del ser. Ahora bien, no llega desde el pensamiento a la transparencia de lo que adviene. Descartes , cn cambio, desde el pensamiento claro osa adentrarse en la naturaleza de la substancia divina. Sin embargo, ¿en qué medida y con qué cautelas lo hace? Gerhard Schmidt insiste en que el sentido del método no es el carácter indubitable de la substancia-yo, sino la existencia de la duda que se aprehende a sí misma. El ser expresado en el yo soy, añade, no es el ser 
absoluto de Dios, pues es un ser temporal, tampoco es el ser objetivo de las cosas. Es origen, espontaneidad del pensamiento. El ser que está detrás del pensamiento es invisible y no puede pensarse. No obstante, de acuerdo con Heidegger, reconoce que luego Descartes cayó en lo cosificante. ${ }^{8}$

Con toda brevedad indicaré a continuación otros rasgos de coincidencia en medio de las discrepancias. Es conocida la reiterativa insistencia de Heidegger en que el ser-ahi cotidiano huye constantemente de su ser para la muerte y asi cae de su "si mismo" propio (cf. parág. 38 de ST). También Descartes dice al final de la Primera Meditación: "Cierta pereza me lleva a la vida ordinaria: como el prisionero que disfrutaba en sueños te una libertad imaginaria..., me deslizo voluntariamente a mis antiguas creencias y me aterra el despertar". Hay en Descartes algo asi como un yo disipado y otro vigilante. Paralelamente Heidegger habla de un "sí mismo" propio y de un "sí mismo" impropio. En ambos el cambio de plano implica una decisión ¿No fue un si mismo propio aquel que en cierto momento erigió resueltamente el mundo modemo?

Descartes dice: Existo incluso cuando me engaño; y Heidegger afima: El ser-ahi también es ser-ahi en la impropiedad.

Descartes independiza el pensamiento frente a la extensión. Heidegger contrapone el parajear al espacio matemático.

e) El nuevo comienzo heideggeriano

Es conocida la objeción de que Heidegger se aleja de todo diálogo posible con la ciencia, mientras que Descartes le ayudó en el camino de su propia constitución y esclarecimiento. Desde una perspectiva actual podriamos decir que Descartes siguió el camino de la ilustración, sin atreverse a entrar en el de la ilustración de la ilustración. Al caracterizarlo con la tenninologia de Horkheimer y Adomo pretendo indicar que Hejdegger coincide con ellos en el dingnóstico de la época. Por ello ha sido tachado de antiilustrador. Él intenta una nueva ontologia con clara conciencia de encontrarse en un final de época. En la actualidad ya resulta más ficil dialogar con la ciencia desde el "ser en el mundo" que desde la evidencia axiomática. Con su idea de la verdad antepredicativa Heidegger se sitúa más allá de Descartes y Husserl, si bien puede conceder al tipo de pensamiento que ellos propugnan una función subordinada, la de la constitución del mundo categorial, la de las tematizaciones cientificas. Pero estas tematizaciones son incapaces por si mismas de aportar el sentido del ser. No obstante, en los siglos pasados han pretendido aportar este sentido, con el consigguiente peligro de desarraigo, totalitarismo y barbarie. La condición y dignidad humana no viene de la ciencia exacta, sino de la vibración de la existencia ante el ser que se muestra y oculta desde un abrirse abismal. No hace falta atribuir esto a un ser mastodóntico, basta con interpretarlo en clave de cómo acontecen nuestras vidas.

Podríamos preguntarnos por qué Heidegger habla tanto de la verdad y tan poco de la certeza, de la teoria del conocimiento, de la actividad del hombre en orden a la apertura del mundo. Él silencia todo esto en aras de su lucla contra el sujeto como fundamento del mundo y como sustrato contrapuesto al mismo. Pero afirma una y mil veces que la apertura acontece a traves del hombre. Sin embargo, esta apertura, esta luz que llega en et acontecer de la verdad, no es un mero estado o proyecto del hombre, sino un alborear originario en el que se abren simultáneamente el mundo y el hombre con sus formas de ser y sus maneras de subjetividad.

8 E.c., parig. 285 
En su propio concepto de ser Heidegger resalta sobre todo lo indisponible. Dice, por ejemplo, que en lo insólito y peculiar de la muerte se abre lo inusitado en todo ente, el ser mismo, que esencia como extrañeza. ${ }^{9}$ La pregunta por la muerte está en relación esencjal con la verdad del ser. La muerte no es una negación del ser o una nada. Por el contrario, la muerte es el supremo testimonio del ser. El ser ahi es un ser abismal, es aquel "entre" que ofrece instante y lugar al "evento" y asi puede pertenecer al ser. No se trata de una filosofia de la muerte, sino de llevar la pregunta del ser a su fundamento. El ser no es el ente, sobre todo si el ente se toma como lo objetivo y dado. En este sentido es la nada. Pero Heidegger pregunta: ¿Qué pasaría si el ser fuera lo gue se sustrae y esencia como esa negación? ¿Es esto hada, o bien la stuprema donacion? ¿No brota de alli todo hacer? La metafisica entiende el ente solamente desde el pensar. ${ }^{10}$

El tomo 13 de la edición Klosterman sobre los Seminarios contiene un Suplemento donde, refiriéndose al pensamiento en Parménides, escribe: "Este pensamiento no es ni un juzgar, ni un demostrar, ni un fundar. En todo caso es un fundarse en lo descubierto. Puro descubrir: "comparece la presencia misma"".

Posiblemente sea Hirosima el lugar donde el encuentro entre Descartes y Heidegger ha llegado a la máxima violencia y a la máxima cercania. La ciencia convertida en instrumento para la muerte ha dejado un suelo desieno en el que quiere implantarse una nueva concepción del pensamiento. La admiración de la claridad empieza a mezclarse con el horror de la claridad.

9 Beitrage zur Philosophie, ed. Nlostermann, t. 65, p. 284.

10 Beitrage, e.c.,p. 246. 